\title{
Comportamento de consumo de moda na Revista Tpm: um olhar critico sobre o corpo, a diversidade e a liberdade da mulherada
}

Fashion buying behavior at Tpm Magazine: a critical look at women's body, diversity and freedom

PELLEGRINI, Bruna Neves I Especialista em Moda

Universidade Estadual de Londrina - UEL I bruna.pellegrini@hotmail.com

\begin{abstract}
Resumo
Este trabalho tem como objetivo analisar o comportamento de consumo de moda na Revista Tpm. A metodologia aplicada foi a análise iconográfica e interpretação iconológica, proposta por Boris Kossoy. Considerando o referencial teórico e a análise final, conclui-se que o comportamento de consumo de moda da Tpm é diferenciado, pois a revista apresenta a diversidade e ressalta a liberdade da mulher.

\section{Abstract}

This study aims to analyze the fashion buying behavior at Tpm Magazine. The methodology employed is the iconographic analysis and iconologic interpretation, described by Boris Kossoy. Considering the theoretical background and the final analysis, results indicate that Tpm Magazine has an unconventional fashion buying behavior, because the magazine shows diversity and emphasizes women's freedom.
\end{abstract}

Palavras Chave: Revista Tpm; Comportamento de Consumo; Moda e Mulher.

Keywords: Tpm Magazine; Consumption Behavior; Fashion and Woman. 


\section{INTRODUC̣ÃO}

A moda se constitui como sendo um dos alicerces da cultura, das práticas simbólicas e da representação das subjetividades. Mesmo contestada como verdade, na emblemática passagem da "queima dos sutiãs" na Europa do final do século XIX, pelas mulheres já havia uma relação cultural entre gênero, moda e política. A peça de vestimenta tipicamente usada por mulheres deixa o arquétipo feminino e se torna uma simbologia da ideologia e também das identidades.

Pensando em simbologia e identidade, Calclini (1995, p. 14) ressalta em sua análise sobre consumo que, as mercadorias servem para pensar, pois elas contribuem para a estruturação da identidade humana e são também, uma forma de comunicá-la socialmente.

Já a imprensa feminina, é um meio de difusão da moda, pois na sociedade da midiatização, a cultura midiática afeta diretamente a sociedade (BRAGA, 2012, p. 36), agindo também no comportamento de consumo dessa sociedade, pois "com a consolidação do campo midiático, a mídia passa a ser um agente fundamental na configuração e difusão do sistema de moda tal como hoje é praticado" (SCHMITZ, 2007, p. 19).

Pensando na forte influência da imprensa destinada à mulher, a autora escolheu analisar a Revista Tpm, em razão de sua ideologia forte e irreverente. De acordo com Hollenbach (2003, p. 252), enquanto as demais revistas propõe um modelo padrão a ser seguido, ditado pela mídia e pela sociedade, a Tpm sugere que cada mulher aja à sua maneira, se posicionando contra padrões impostos e a favor da diversidade.

Nesse sentido, será possivel que a Revista Tpm transmita sua ideologia por meio de seus editoriais de moda também? Afinal, como é o comportamento de consumo de moda na Revista Tpm? Essas respostas virão à tona com a análise proposta por Boris Kossoy (2014), que para delimitação do corpus será aplicada em quatro editoriais de moda do ano de 2015.

A relevância deste trabalho se dá pela perspectiva de que a moda contribuiu para redefinir identidades sociais e "desfigurou algumas das fronteiras simbólicas entre o masculino e o feminino, sendo motor e reflexo das mudanças da condição feminina" (JOAQUIM; MESQUITA, 2011). Dessa forma, considera-se que a importância de analisar o comportamento de consumo de moda na revista proposta dá-se também, pela necessidade de compreender a influência da imprensa feminina no comportamento de consumo de moda e de sua interferência na construção e no desenvolvimento da identidade da mulher. 


\title{
2 COMPORTAMENTO DE CONSUMO DE MODA
}

Por meio deste capítulo pretende-se abordar o comportamento de consumo de moda, com o intuito de entender como ele funciona e qual é a sua intervenção social. De acordo com Canclini (1995, p. 65), o ato de consumir é um ato de pensar.

\begin{abstract}
Consumir é tornar mais inteligível um mundo onde o sólido se evapora. Por isso, além de serem úteis para a expansão do mercado e a reprodução da força de trabalho, para nos distinguirmos dos demais e nos comunicarmos com eles, como afirmam Douglas e Ishewood (2004)',"as mercadorias servem para pensar"
\end{abstract}

Nesse sentido, Schmitz (2007, p. 13) afirma que na obra Consumidores e Cidadãos, Canclini (1995, p. 14) "não desconsidera a competição de classes em sua análise do consumo, mas propõe um deslocamento do olhar sobre o mercado, colocando sua importância e poder na estruturação e constituição das identidades". Sendo assim, entende-se que o ser humano usa o consumo como forma de construir uma identidade própria e comunicá-la à sociedade. Abordando o consumo como forma de comunicação, Miranda (2014, p. 14), explica que a troca entre as pessoas vai além das mercadorias, "o que é compartilhado são valores, ideais, estilos... Ou seja, existe uma filosofia de vida que direciona os atos de consumo".

Se tratando de moda, é importante salientar que no vestuário isso se torna ainda mais forte, pois ele é público e privado ao mesmo tempo, "a moda possui, entre outras, duas facetas singulares: a busca pela individualidade e a necessidade de integração social", ou seja, é um "ato de narcisismo e de generosidade, porque é para si e também para o outro", (MIRANDA et al., 1999, p. 3). A moda é considerada uma forma de expressão simbólica, porque "até quando não seguem a moda as pessoas estão comunicando algo de si, é sinal de idade ou de possuir opiniões e crenças envelhecidas ou ainda de não aceitar padrões estabelecidos" (LURIE, 1997 apud MIRANDA, 1998, p. 36), ou seja, por meio do vestuário é possível constatar opinião, atitude e até mesmo alguns valores.

Apesar desse processo de comunicação ser explorado por toda a sociedade, as mulheres são mais envolvidas com a moda do que os homens, pois como afirma Thompson (1997 apud MIRANDA, 2014, p. 76), existe uma associação histórica entre moda e feminilidade, "a relação entre auto percepção pública e a dimensão relativa ao vestuário são muito fortes para o sexo feminino", (SOMOLON, 1992 apud MIRANDA, 2014, p. 76).

DOUGLAS, M.; ISHERWOOD, B. El mundo de los bienes. Hacia una antropologia del consumo. México: Grijalbo-CNCA, 1990. [ed. bras.: O mundo dos bens. Rio de Janeiro: Editora UFRJ, 2004]. 
Além disso, Simmel (1904 apud MIRANDA et al., 1999, p. 3), afirma que o ser humano tem uma tendência psicológica à imitação, isso acontece porque "ao imitar não só transfere a atividade criativa, mas também a responsabilidade sobre a ação dele para o outro", pensando nisso o autor conclui que a "moda é a imitação de modelo estabelecido que satisfaça a demanda por adaptação social, diferenciação e desejo de mudar, sendo baseada pela adoção por grupo social", (SIMMEL, 1904 apud MIRANDA et al., 1999, p. 3).

Assim, entende-se que a identificação da mulher com a ideologia de uma revista feminina pode tornar esta publicação uma espécie de grupo social a ser adotado. Pensando nisso, o próximo capítulo pretende abordar moda, imprensa feminina e a influência de ambas na vida da mulher.

\section{A IMPRENSA FEMININA BRASILEIRA E A MODA}

Para o consumo de moda ser concretizado, ele deve ser comunicado socialmente, portanto, acredita-se que a imprensa feminina seja um forte meio de comunicação da moda. "O processo de classificação e da comunicação simbólica passa pelo reconhecimento social: o significado associado ao produto deve ser claramente estabelecido e entendido por segmento da sociedade para que possa se construir enquanto símbolo", (GRUBB; GRATHWOL, 1967 apud MIRANDA, 1998).

Dessa forma, entende-se que a mulher pode ter esse reconhecimento social com as publicações femininas e através delas entender os significados da moda. Esse reconhecimento se dá pela forte influência da imprensa feminina em relação à sociedade, especialmente à mulher - seu público alvo.

O poder da imprensa destinada à mulher pode ser atribuído aos seus conteúdos, que como explica Buitoni (2009), à primeira vista, parecem neutros e até mesmo fracos, mas se olharmos mais a fundo, podemos observar que são mais "ideologizados" do que aos destinados ao público geral. "A relação entre a imprensa feminina e a mulher implica questões mais abrangentes, como o papel social da mulher ou sua participação política. E aí entra a ideologia", (BUITONI, 2009, p.21).

Sendo assim, entende-se que a imprensa feminina busca ser um meio de representação da mulher, a fim de conquistar a identificação de seu público com o seu conteúdo. No entanto, observa-se que, muitas vezes, a imprensa feminina não consegue acompanhar de forma efetiva as mudanças da mulher na sociedade:

[...] continuo a procurar mulheres de verdade nas revistas femininas, embora saiba que a publicidade e consumo lidam principalmente com mitologias. Também entendo que há um paradoxo implícito no discurso dessas publicações: 


\begin{abstract}
tentar abrir brechas para a transformação de padrões e publicar páginas de anúncios de cosméticos e artigos de luxo, aconselhar dietas, apontar celebridades como imagem ideal e modelo de comportamento. (BUITONI, 2009, p.14).
\end{abstract}

Dessa forma, Buitoni (2009, p. 14), questiona como fazer uma revista vendável sendo "femininamente" correta, e em seguida responde "algumas tentativas como a americana Ms. e a brasileira TPM são a prova de que é possível trilhar outros caminhos". O próximo capítulo terá o objetivo de apresentar a revista Tpm, todavia, no capítulo presente, a apresentação da imprensa feminina como um meio de representação da mulher, se deu pela necessidade da autora em mostrar que, tanto a imprensa feminina quanto a moda são capazes de contar a história da mulher.

Enquanto a moda atua como um reflexo da sociedade, "através da análise do vestuário e outros itens passíveis de moda pode-se definir o momento histórico, os valores, o comportamento daquela sociedade." (LAVER, 1995 apud MIRANDA, 1998, p. 29), a imprensa feminina "foi instrumento de democratização da moda, trouxe informações sobre sexo, contribuiu para a revolução sexual e, todavia sugere a colocação de próteses como uma grande conquista de beleza e identidade", (BUITONI, 2009, p. 15). Questionando os padrões estéticos apresentados nos periódicos femininos, a autora, ainda compara: "Se antes se achava que o espartilho restringia a liberdade, hoje é fortíssima a indução para colocar silicone nos seios. Passou-se para a invasão corporal, que é aceita como natural e se transformou em objeto de desejo de milhares de adolescentes brasileiras".

Dessa forma, Buitoni (2009, p. 15), sugere que a moda pode ser uma forma de libertar a mulher desses padrões impostos socialmente, pois "a moda do vestiário propõe linhas e tendências e também abre espaço para cada uma usar a roupa que quiser no horário e ocasião que desejar". Segundo Buitoni (2009, p. 12), moda e imprensa feminina sempre caminharam lado a lado, "desde o século XIX, as publicações femininas brasileiras traziam elementos da moda, auxiliando no processo de democratização do gosto".

O próximo capítulo pretende apresentar o objeto de estudo deste trabalho, a Revista Tpm e abordar as suas diferenças em relação as demais publicações femininas do País.

\title{
4 REVISTA TPM: UMA NOVA PROPOSTA EDITORIAL NA IMPRENSA FEMININA
}

A revista Tpm tem uma história atípica, pois ela nasceu a partir de um periódico masculino - a revista Trip, que foi criada em 1986, junto com sua editora homônima. De acordo com o site da editora ${ }^{2}$, a revista Trip é uma 2 Site da Editora Trip em <http://www.tripeditora.com.br/marcas-trip/>. 
publicação que tem uma incessante busca pelo novo. Segundo Costa (2007, p.11), ela se diferencia entre as demais revistas masculinas, a Trip "ganhou o rótulo de revista do homem moderno e tornou-se também palco de discussões sobre a nova masculinidade.".

A originalidade do periódico acabou chamando a atenção não apenas dos "homens modernos", mas também das mulheres, o que fez a editora constatar que $25 \%$ dos leitores da Trip era composto pelo público feminino e foi assim que, em maio de 2001, foi lançada a primeira edição da versão feminina da revista, a Trip Para Mulheres (TPM).

Segundo Euzébio (2010 apud SALTARELLI, 2012, p. 2), a proposta de Lima, fundador e editor da Trip, era romper com os modelos editoriais do segmento feminino, que, na sua concepção, menosprezavam a inteligência da mulher. Essa intenção pode ser observada desde o título da revista, já que a sigla "TPM" sugere interpretações interessantes:

\begin{abstract}
A sigla TPM, Trip Para Mulher, refere-se também à tensão pré-menstrual, indicando o tipo de público que a revista pretende atingir: mulheres ousadas, fortes, que se permitem ter variações de humor - como acontece com a maioria das mulheres durante a TPM -, que não se encaixam nos estereótipos femininos tradicionais, nem naqueles que as outras revistas femininas propõem, (HOLLENBACH, 2003, p. 249).
\end{abstract}

Entende-se, então, que a preocupação da revista em buscar a identificação do público está presente desde o seu nome. Além disso, no Mídia Kit da Editora Trip ${ }^{3}$, a Tpm se apresenta como uma alternativa às mulheres que não se sentem representadas pelas revistas femininas disponíveis no mercado editorial e propõe novas maneiras de falar de mulher e com a mulher. De acordo com Buitoni (2009, p. 207), o periódico realmente se sobressai. "A Tpm apresenta matérias inteligentes e aprofundadas, ao lado de seções de roteiro cultural e comentários humorísticos - coisa rara em imprensa feminina e propõe outras visões de consumo, embora dentro de uma economia capitalista."

A Tpm, assim como as demais revistas destinadas à mulher, veicula reportagens sobre assuntos que fazem parte do universo feminino, mas faz isso de modo diferente das demais, que apontam um manual de "como fazer" que, segundo Buitoni (2009, p. 192), na maioria das vezes se assemelham a receita de um bolo, "dando as diretrizes para ser bonita, bem-vestida e morar bem. Tudo vira receita de como se deve fazer para ser o modelo de mulher apresentado".

3 Midia Kit da Revista Tpm. Disponível em: <http://www.tripeditora.com.br/wpcontent/uploads/2015/04/Trip-Tpm-Mi\%CC\%81dia-Kit-2015.pdf>. 
Com essa ideologia original e inovadora, atualmente a Tpm tem periodicidade mensal e a tiragem média de 35 mil exemplares. De acordo com o Mídia Kit da editora, o público que acessa o site da Tpm é formado por $92 \%$ de mulheres e $8 \%$ de homens, sendo $69 \%$ acessado por pessoas de 26 a 45 anos, $18 \%$ de 46 anos ou mais, $12 \%$ de 19 a 25 anos e $1 \%$ de até 18 anos.

Sendo assim, pretende-se verificar se a ideologia da revista também abrange os seus editoriais de moda. Para isso, a metodologia aplicada será a "análise iconográfica e interpretação iconológica" - proposta por Boris Kossoy em seu livro "Fotografia \& História", que será apresentada no próximo capítulo.

\section{METODOLOGIA: ANÁLISE ICONOGRÁFICA E INTEPRETAC̣ÃO ICONOLÓGICA}

Considerando que este artigo pretende analisar os editoriais de moda da revista Tpm, entende-se a relevância de optar por uma metodologia específica para fotografias. Segundo Kossoy (2014, p. 54), autor da metodologia utilizada, "assim como a palavra é a expressão de uma ideia, de um pensamento, a fotografia - embora se trate de uma imagem técnica produzida por meio de um sistema de representação visual - é também a expressão de um ponto de vista". Então, acredita-se que as fotografias dos editoriais de moda da Tpm sejam um meio de expressão do ponto de vista da revista.

No entanto, Kossoy (2014, p.43) defende que fotografias representam um momento histórico específico "o processo que deu origem a uma representação fotográfica tem seu desenrolar em um momento histórico específico (caracterizado por um determinado contexto econômico, social, político e cultural", o que permite que a análise dos editoriais de moda da revista, também considere esses fatores históricos apresentados no discurso da Tpm, pois é necessário compreender esses aspectos, para entender o conteúdo dos editoriais, afinal, como afirma Barnard (2003, p. 120), o significados das roupas não são tão óbvios quanto parecem.

Pode ser fácil dizer o que significariam se usados na nossa própria cultura, mas a possibilidade de que o significado só seria disponível numa, e não noutra cultura, é suficiente para que se tenha dúvida sobre ser o significado uma propriedade da peça de roupa. Afinal de contas, se o significado estivesse simplesmente no traje, como a cor vermelha, então a leitura poderia ser feita por pessoas provenientes de todos os tipos de cultura.

Por tanto, para concluir a análise de forma eficaz, Kossoy (2014, p. 109) propõe duas formas distintas de análise, a iconográfica e a iconológica. A iconográfica tem o objetivo de detalhar o conteúdo da imagem de forma literal. Já a iconológica, busca o significado interior do conteúdo da fotografia, 
no plano da interpretação. "A comunicação não-verbal ilude e confunde. Devese, no entanto, perceber na imagem o que está nas entrelinhas, assim como o fazemos em relação aos textos", (KOSSOY, 2014, p. 130). Além disso, ressalta que é necessário considerar manipulações e diferentes interpretações de uma imagem.

\footnotetext{
Tais manipulações/interpretações, que muitas vezes se confundem em uma só atitude, envolvem: o fotógrafo que registra - e cria - o tema; o cliente ou contratante, que lhe confiaamissãoderetratarou documentar, acasapublicadora [...] que a utiliza segundo determinada orientação editorial; os diferentes receptores (contemporâneos à sua produção ou que tomarem contato com ela posteriormente à sua realização), que a veem - seja em sua forma original, seja impressa - e reagem de formas totalmente diversas [...] (KOSSOY, 2014, p. 120).
}

Portanto, é importante lembrar que no caso, a Tpm é o cliente contratante e a casa publicadora ao mesmo tempo, enquanto os receptores geralmente são leitores da revista e, por isso, provavelmente se identificam com a sua ideologia e assim, possivelmente, têm repertórios culturais semelhantes aos da Tpm.

Dessa forma, entende-se a necessidade de considerar todos esses fatores para a análise dos editoriais de moda, pois é importante entender as fotografias como imagens que carregam significados e ideologias.

Sendo assim, o próximo capítulo pretende analisar por meio da metodologia apresentada, os editoriais de moda da Tpm, a fim de verificar se, de fato, eles representam a ideologia da revista.

\title{
6 ANÁLISE: RESULTADOS E DISCUSSÃO
}

\author{
6.1 Editorial de Moda: a Hora Que Estoy Aquí - edição no 149 dez.,2014/ \\ jan.,2015.
}


Figura 1- imagem do editorial de moda

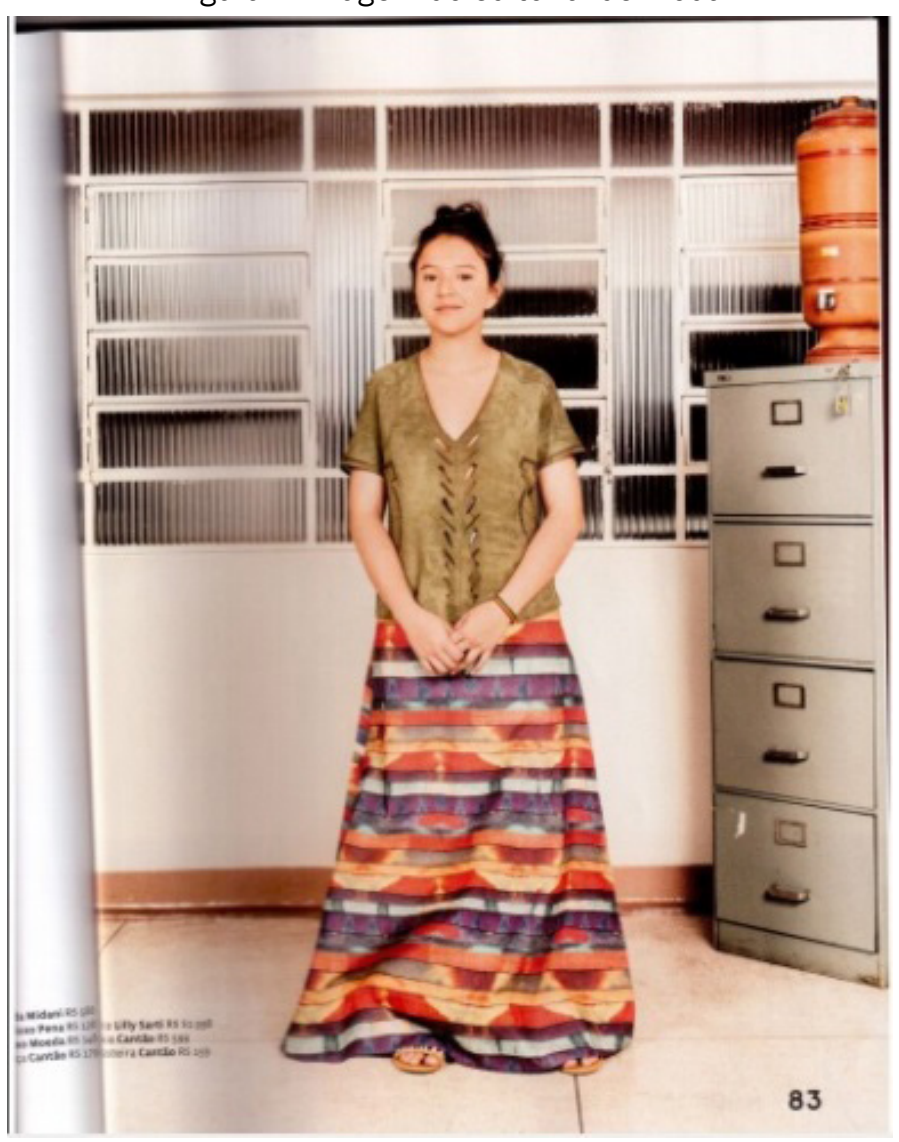

Fonte: Alex Batista (Revista Tpm, no 149, p. 83)

Conforme sugere a metodologia aplicada, a análise deve começar pela iconografia, descrevendo o editorial. Esta edição marca a última revista do ano de 2014 e também a primeira de 2015. Quem fotografou o editorial foi Alex Batista - que tem sua trajetória profissional marcada entre a moda e as ruas, pois imagens urbanas são muito presentes em seu portfólio ${ }^{4}$.

O título "A hora que estoy aqui", já sugere do que se trata o editorial de moda, que segue com a linha fina "uma paraguaia e uma boliviana, que vivem no Brasil, exibem conforto e estilo com sotaque castelhano". A primeira "modelo" apresentada é a Shirley Lujan, uma estudante, de 16 anos - conforme conta a descrição da revista:

Shisley chegou a São Paulo há dez anos. Tinha apenas 5, mas diz que se lembra de cada detalhe da mudança. Junto com ela vieram a mãe, o padrasto e duas irmãs mais velhas. A família vive dos ganhos da mãe, que trabalha como costureira em confecções do Brás e do Bom Retiro. As irmãs mais velhas seguiram caminhos diferentes, se casaram e voltaram para o Paraguai. Mas Shirley não pretende fazer o mesmo, há muito tempo se acostumou com o português, 
seu "idioma preferido". Por aqui, ela espera todo ano ansiosamente pelo Carnaval [...]. (Revista Tpm, ed. 149, p. 81).

Depois desse texto de apresentação, é possível perceber a intenção da Tpm em transformar o editorial de moda em mais uma matéria na revista.

Nas imagens, Shirley veste roupas casuais, coloridas, estampadas e soltas no corpo, que sugerem a preocupação da revista em vesti-la de forma excêntrica, com o intuito de valorizar sua cultura diferente. Além disso, nas duas fotos em que aparece os pés da menina, ela está usando sapatos baixos; primeiro um tênis e depois uma rasteirinha, o que demonstra conforto. Quanto ao cenário, as imagens parecem ter sido tiradas em um colégio, pois têm carteira, janela, armário e quadro negro, ou seja, o ambiente tipicamente frequentado por Shirley.

Na segunda parte do editorial, é apresentada a segunda "modelo", Virginia Marques de Quispe, uma costureira de 30 anos de idade.

\begin{abstract}
Virginia deixou a cidade de La Paz, na Bolívia, aos 22 anos. Veio sozinha para o Brasil em busca de melhores condições de vida. Chegou ao bairro do Brás, em São Paulo, para trabalhar como costureira. Levou uma vida difícil como funcionária de uma confecção gerida por bolivianos, largou o emprego e passou a fazer consertos e pequenas reformas em roupas na casa onde moda, no bairro de Jaraguá. "A vida na confecção é muito dura. Hoje, trabalho em casa, mas estou atrás de um novo emprego", diz. Com a ajuda do Cami (Centro de Apoio e Pastoral do Imigrante), Virginia busca uma nova função, mas garante não pretende voltar à Bolívia. "Só a passeio, para visitar minha mãe e meus irmãos."
\end{abstract}

Na primeira foto, Virginia aparece de macacão e tênis, na segunda de blusa listrada e na terceira e última, vestindo um conjunto de calça com regata e tênis nos pés. Em relação ao cenário, não dá para ter certeza de onde ela está, mas em razão da segunda fotografia - com as cadeiras de plástico atrás da personagem, tem-se a impressão de que ela está no Centro de Apoio e Pastoral do Imigrante, citado na descrição do editorial. 
Figura 2- Imagem do editorial de moda

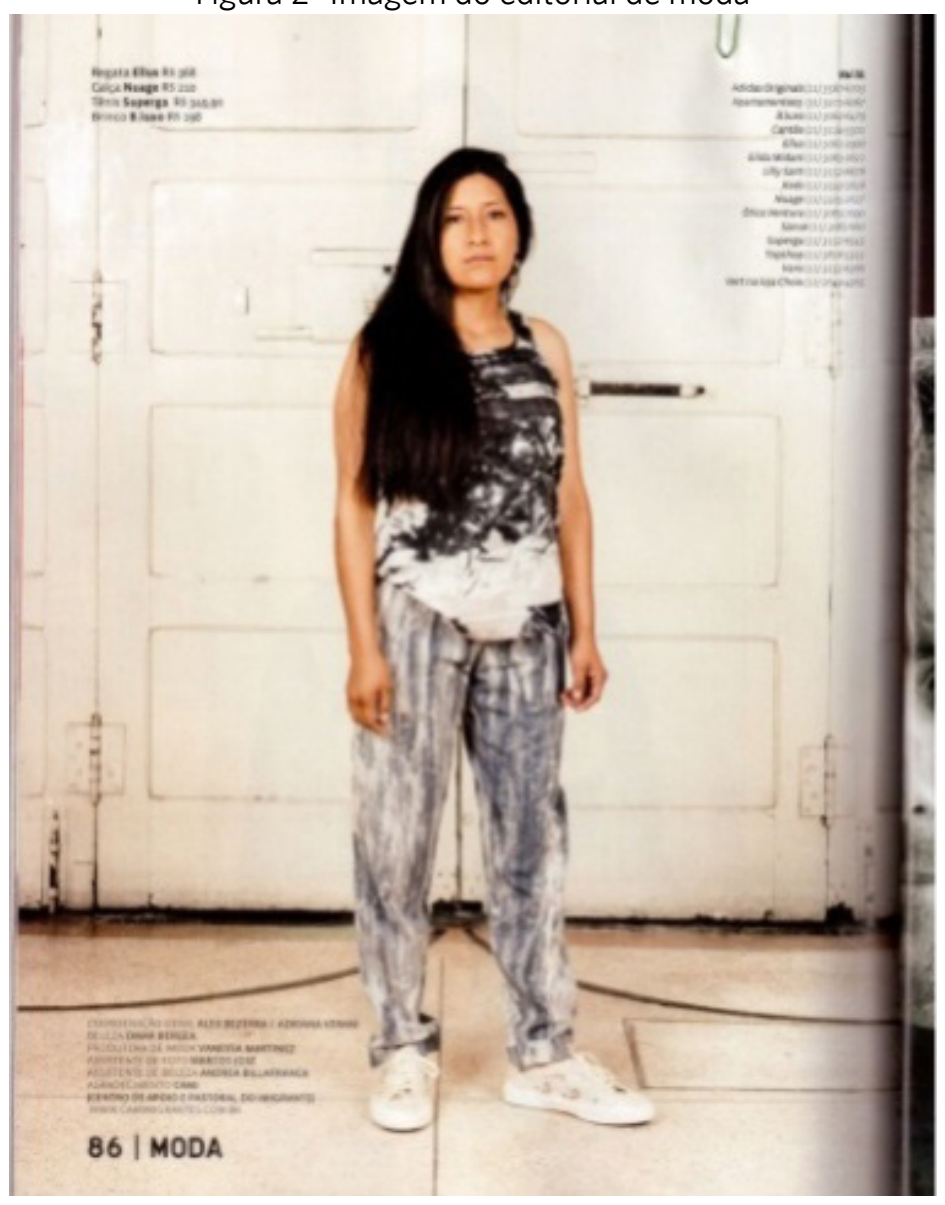

Fonte: Alex Batista (Revista Tpm, o 149, p. 86)

Partindo para a análise iconológica, por meio dessa sessão de fotos, foi possível perceber que a Tpm se preocupa mais em "contar histórias" e mostrar diferentes estilos, do que passar tendências de moda às suas leitoras, pois apesar das roupas usadas serem de marcas de moda conhecidas, como Adidas, Ellus, Keds, Vans, entre outras, o foco principal das fotos são as personagens.

A escolha da revista por uma Paraguaia e uma Boliviana, demonstra o desejo da Tpm em contar as histórias particulares das imigrantes, de idades diferentes, com sonhos diferentes, mas dificuldades em comum. Além disso, demonstra a intenção da revista em apresentar diferentes culturas e estilos de moda no editorial, e também, quebrar padrões estéticos - um assunto frequentemente abordado na Tpm.

Observa-se, também, a preocupação da revista com questões sociais, no sentido de apresentar à leitora a realidade de pessoas de diferentes classes sociais e mais, a escolha de uma costureira pode significar uma tentativa da Tpm de apresentar a realidade "por trás" da moda e as diversas dificuldades de quem trabalha nesse setor aparentemente glamouroso.

Por fim, é importante salientar o fato de a revista optar por usar mulheres comuns como modelos, algo atípico nos editoriais de moda das demais revistas femininas do Brasil. 


\subsection{Editorial De Moda: Na Cidade - edição no 150 fev./ 2015.}

Figura 3- Imagem do editorial de moda

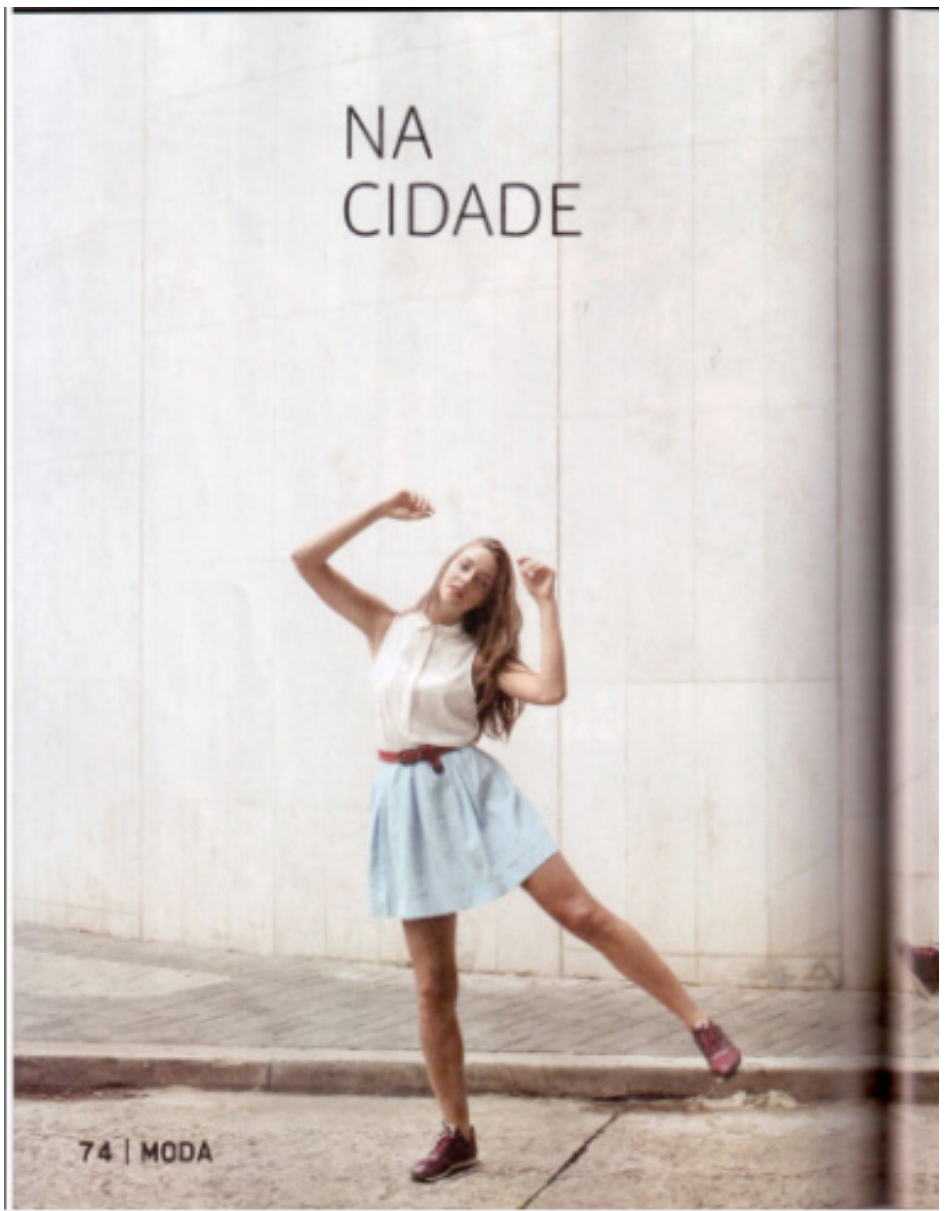

Fonte: Pablo Saborido (Revista Tpm, no 150, p. 74)

O fotógrafo deste editorial é o mesmo dos próximos dois que serão apresentados neste trabalho, o argentino Pablo Saborido ${ }^{5}$, radicado em São Paulo. Ele ficou conhecido por sua série fotográfica "Paisagens próximas do fim do mundo", em que retrata a cidade de Comodoro Rivadavia, popularmente conhecida como a capital argentina do petróleo na região de Patagônia.

As imagens foram feitas em 2009, mas estiveram em exposição em fevereiro de 2014, na cidade de São Paulo. Elas mostram locais bucólicos que sofreram intervenções de anos da exploração do petróleo. Em uma entrevista concedida ao $\mathrm{G} 1^{6}$, o fotógrafo demonstra sua preocupação social e política dizendo que se ocupa atualmente registrando espaços inutilizados da cidade - o que também sugere uma preocupação por parte da Tpm, em escolher um fotógrafo que não seja exclusivamente do meio da moda e que tenha um senso crítico político e social.

5 Portfolio do fotógrafo Pablo Saborido. Disponível em: <http://pablosaborido.com/>. 
Como a maioria dos editoriais da Tpm, esse também vêm acompanhado de uma descrição: "As ruas aproximam, combinam, afastam. Variações sobre encontros e desencontros pontuados por algum vermelho." Nas duas imagens da primeira página, a jovem modelo aparece sozinha, na rua, com camisa e saia rodada, marcada na cintura - indumentária tipicamente feminina, porém, nos pés ela revela um tênis - o vermelho citado na descrição da imagem. Virando a página é revelado o "encontro", também citado na descrição, pois a jovem aparece acompanhada de um modelo masculino. As cores continuam nos tons pálidos de amarelo e azul, mas a presença do vermelho torna-se mais marcante. Além disso, as vestimentas da modelo são soltas, nada muito justo é apresentado, e nos pés, um outro tênis vermelho ganha destaque.

Figura 4- Imagem do editorial de moda

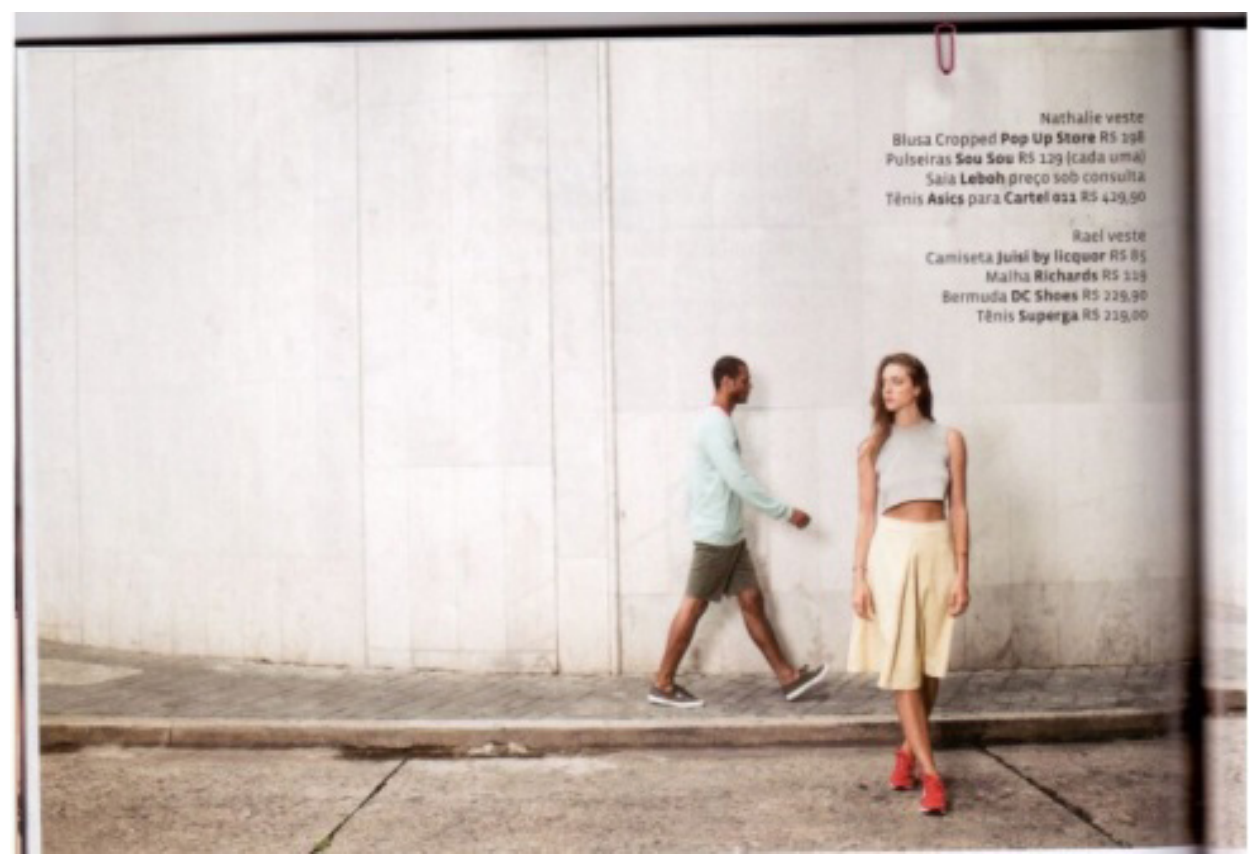

Fonte: Pablo Saborido (Revista Tpm, no 150, p. 76)

Na página seguinte, os modelos aparecem de costas um para o outro, como um "desencontro" e ela veste um shorts jeans justo, junto a uma blusa solta em tons de banco e vermelho, nos pés, novamente tênis. Na última página, ela aparece com três roupas diferentes, primeiro com shorts e blusa em preto e branco, depois com um vestido vermelho e por último, com um vestido branco fluído, com detalhes em preto e cintura marcada. Em todos os momentos a modelo usa tênis nos pés.

De modo iconológico, sabendo que a Tpm manifesta-se em prol da igualdade entre homens e mulheres, podemos observar a presença constante do tênis como uma forma da revista pregar essa igualdade entre os gêneros, já que ambos o estão usando em todas as imagens. Além de assegurar comodidade à mulher, mas sem perder a feminilidade apresentada nas roupas da modelo, também podemos observar, que ela está sempre em movimento nas imagens, transmitindo leveza ao receptor. 
Por outro lado, sabe-se que a Tpm traz em suas páginas reflexões sobre o padrão estético imposto pela mídia, para as mulheres, mas a modelo escolhida para o editorial está exatamente dentro desses padrões. Ela é alta, magra, loira de cabelos compridos e olhos claros - o perfil tipicamente apresentado em todas as outras revistas femininas, ou seja, nesse ponto, no presente editorial, a Tpm não se diferenciou das demais. No entanto, o modelo que acompanha a jovem é negro, o que mostra uma preocupação da revista em contrapor um "padrão" com algo que possa ser alvo de preconceito; e a Tpm procura se posicionar contra todos os tipos de preconceitos.

\subsection{Editorial De Moda: Tem Mas Acabou - edição no 151 mar./ 2015.}

Este editorial também foi fotografado pelo argentino Pablo Saborido, e a frase que acompanha as imagens é: "No vazio deixado pela água em Atibainha, que faz parte do sistema Cantareira, em São Paulo, roupas para o fim do mundo. Porque se é pra acabar, que seja com estilo, porra!". Assim, a revista já sugere que a sessão de fotos trate da escassez de água que dominou a metrópole, além de mostrar a irreverência e a jovialidade pretendida pala Tpm. O cenário do editorial é caótico e demonstra a preocupação política por parte da revista e, também, do fotógrafo. A primeira imagem é marcada por um carro velho e despedaçado, meio ao rio Atibainha, onde a modelo parece representar as pessoas que sofrem com os danos de situações como essas na cidade de São Paulo. A roupa é simples e preta.

Figura 5- Imagem do editorial de moda

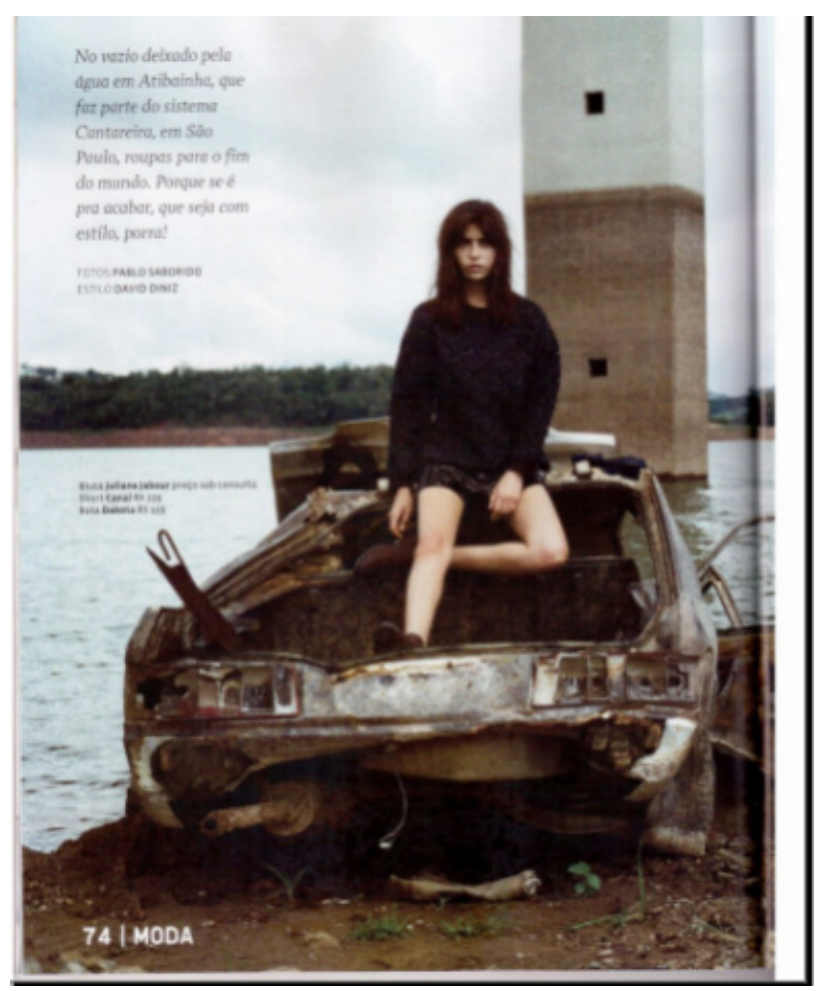

Fonte: Pablo Saborido (Revista Tpm, no 151, p. 74) 
Nas próximas páginas, a modelo aparece de maiô, tênis, vestidos leves - diversos tipos de vestimenta, como se estivesse pronta para "encarar o fim do mundo", como diz a revista. No meio do editorial, é apresentado um modelo homem em segundo plano, para acompanhar a modelo - como se fosse mais um "personagem" sofrendo pelos danos da cidade.

Iconológicamente, as roupas soltas da modelo sugerem liberdade - aquela valorizada e apresentada em 1970. Os sapatos baixos e até masculinizados, além de adequados para o cenário das fotografias, retrata a mulher Tpm, livre, em busca de conforto e assídua da moda unissex.

Figura 6- Imagem do editorial de moda

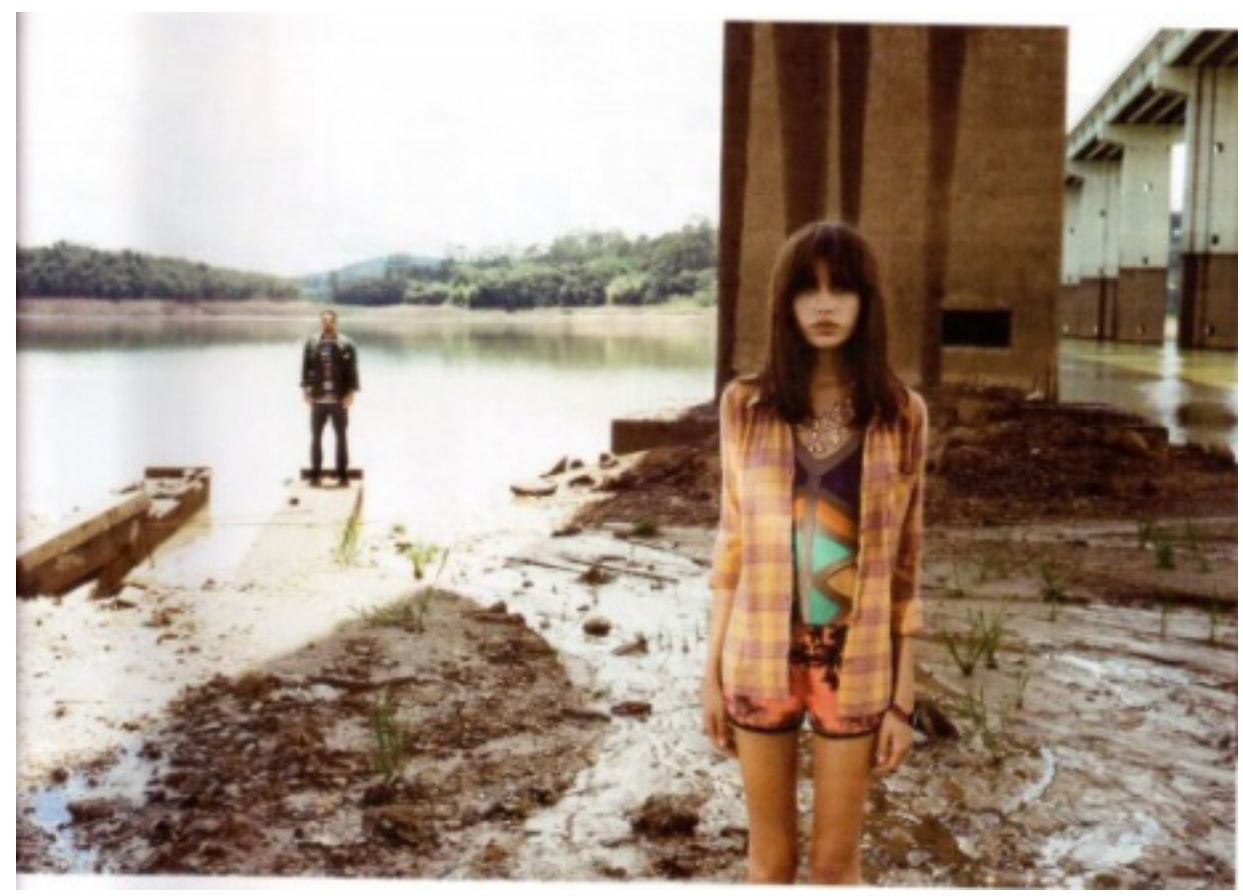

Fonte: Pablo Saborido (Revista Tpm, no 151, p. 83)

Analisando o tipo físico magro da modelo e sabendo que essa edição da revista foi um "especial da bunda: o lado B do Brasil", em que ela fez críticas ao padrão brasileiro, em que nádegas avantajadas são tão valorizadas e mulheres que não atendem à esse padrão sofrem em razão disso, entende-se que a escolha da modelo magra, sem muitas curvas, também ocorreu para ir contra o padrão Nacional.

Além de que o cenário é o oposto do que geralmente é apresentado pelas revistas femininas nos editoriais de moda, que costumam ser luxuosos e ostentadores.

\subsection{Editorial De Moda: Altos e Baixos - edição no 152 abr./ 2015.}

Este é mais um editorial fotografado pelo Pablo Saborido, e começa apresentando o seguinte texto: "Da galera da moto à turma da ginástica olímpica. Os gostos são diferentes, assim como os sonhos e também os tamanhos. Do 
manequim 34 ao 42 o que importa é estar confortável em seu estilo".

Figura 7 e 8 - Imagens do editorial de moda
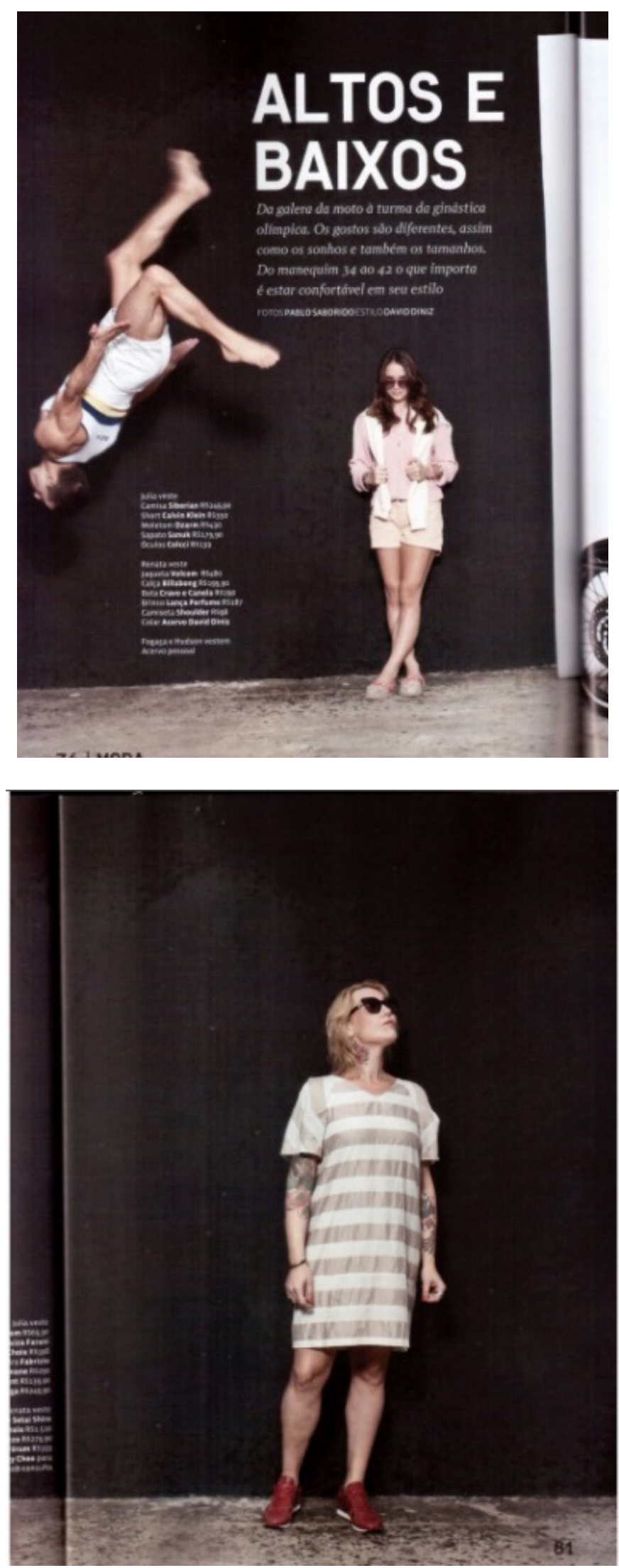

Fonte: Pablo Saborido (Revista Tpm, no 152, p. 76, 81)

As duas primeiras páginas já mostram a diversidade proposta pela revista, três estilos diferentes são apresentados - um atleta saltando, uma moça 
com roupa casual, mas elegante e, aparentemente, dois motoqueiros. Depois, virando a página, as duas mulheres são fotografadas - uma em cada página. As duas usam shorts da Levi's, a mais jovem aparece de camiseta estampada e jaqueta preta por cima e a mais velha camisa branca e, também, jaqueta preta por cima. Na próxima página, a moça está plantando bananeira com uma roupa causal e a mulher mais velha aparece de vestido, com tênis e diversas tatuagens. Para finalizar, a mesma jovem que apareceu plantando bananeira, é fotografada em pé, com um vestido casual, uma jaqueta larga e tênis. Ao lado, mais um texto, com o título "tamanho único: cada um tem o seu".

Julia Simone Pasquini tem 1,56 metro, calça 36 e treinou ginástica olímpica por dez anos - abriu mão da vida de atleta para se dedicar à faculdade de psicologia, que logo termina. Renata Aimée, 1,76 metro, calça 39, adora andar de skate com o filho, é formada em gastronomia e trabalha com administradora de um restaurante. Julia tem 20 anos e Renata 36. Julia veste 34, Renata, 42. Cada uma tem sua paixão, suas crenças e também seu tamanho. Vestir só é único quando pensamos que cada um traja o que bem entender. Vestir só é único quando cada um expressa a si mesmo com liberdade, exibindo ou cobrindo. Hudson Miguel é atleta, está focado na Olimpíada do Rio e calça 38. Henrique Fogaça é chefe de cozinha, jurado do Masterchef, pilota uma Harley Davidson e calça 43. (Revista Tpm, edição 152, p. 82).

Considerando este texto, as imagens e a proposta dessa edição, que na capa já diz "especial peso", fica clara a intenção da Tpm em usar o editorial de moda como mais uma reportagem da revista, para mostrar pessoas diferentes, com gostos e tamanhos diferentes - pois lutar contra os padrões estéticos impostos socialmente faz parte da ideologia da publicação, que além do peso, trouxe uma mulher mais velha e tatuada, outra tentativa de quebrar os padrões e mostrar a liberdade de cada um em todos os sentidos. Também é importante ressaltar a atitude da revista em usar pessoas comuns, e não modelos, para protagonizar o editorial de moda, o que reforça ainda mais a irreverência da Tpm.

\section{CONSIDERAC̣ÕES FINAIS}

Considerando a ideologia da revista apresentada, o referencial teórico deste trabalho e a metodologia aplicada - que considera o contexto históricos das imagens, é possível constatar que os editoriais de moda da Tpm trazem uma proposta diferente. O comportamento de consumo de moda da revista, não trata de tendências de moda, ele traz diversas possibilidades de moda, de acordo com o tema escolhido para o editorial, o que sugere que cada mulher, ou seja, cada leitora faça as suas escolhas de acordo com a sua personalidade. 
É possível observar também que, a diversidade está inserida nos editoriais, pois nas quatro edições analisadas, foram veiculadas fotos de mulheres e homens com perfis completamente distintos em relação à idade, tipo físico, classe social e estilo. No entanto, em uma revista que frequentemente critica os padrões estéticos impostos pela mídia, especialmente em relação ao peso, esperava-se encontrar ao menos uma mulher fora do padrão estético da magreza, tão presente em nossa sociedade e especialmente na moda. Por outro lado, foi possível encontrar diversas roupas que contemplam outras formas de silhueta, que não tem como objetivo principal evidenciar as curvas femininas. Essas novas formas de silhuetas apresentadas, funcionam como uma declaração de poder da mulher sob seu próprio corpo.

Além disso, sentiu-se a preocupação da revista em trabalhar o editorial de moda como mais uma matéria da edição, trazendo mais conteúdo para a revista - o que reforça sua intenção em explorar a inteligência e o senso crítico da mulher.

É interessante observar, também, que entre tantas peças de roupas apresentadas nos editoriais, uma delas se fez mais presente: os sapatos baixos. Nenhum sapato de salto-alto foi abordado e o calçado mais utilizado em todas as edições foi o tênis. A forte presença desse calçado mostra o desejo da Tpm em propor que as mulheres se libertem dos saltos-altos que limitam seus passos e abram espaço para o conforto, conforto este, muito importante atualmente, quando geralmente as mulheres têm rotinas tumultuadas.

De maneira geral, conclui-se que, existe uma tentativa de ruptura por parte dos editoriais de moda da Revista Tpm, em relação aos editorais tradicionais. A revista apresenta um comportamento de consumo de moda mais flexível, que acompanha a ideologia de pluralidade proposta pelo periódico. Sendo assim, acredita-se que, por meio de seus editoriais, a Tpm apresenta a moda de forma mais leve e, ao mesmo tempo, mais crítica; o que pode levar a mulher a usar a moda como uma aliada neste processo atual de ressignificação cultural e social da identidade feminina.

\section{REFERÊNCIAS}

BARNARD, Malcolm. Moda e Comunicação. Rio de Janeiro: Rocco, 2003.

BRAGA, José Luiz. Circuitos versus campos sociais. JANOTTI JUNIOR, Jeder; MATTOS, Maria Ângela; JACKS, Nilda (Org.). Mediação \& Midiatização. Salvador: EDUFBA, 2012. p. 31-52.

BUITONI, Dulcília Helena Schroeder. Mulher de papel: a representação da mulher pela imprensa feminina brasileira. 2. ed. São Paulo: Summus, 2009. 
CANCLINI, Néstor García. Consumidores e cidadãos: conflitos multiculturais da globalização. 7. ed. Rio de Janeiro: Editora UFRJ, 1995.

COSTA, Camilla Maria Lima. O que quer a mulher: lugar de fala e representação de gênero na revista TPM. 2007. Monografia (Graduação em Comunicação) - Faculdade de Comunicação, Universidade Federal da Bahia, Salvador, 2007.

HOLLENBACH, Gabriela. O Casamento e a Tpm: novos tempos, novos sentidos. Em Questão, Porto Alegre, v.9, n. 2. jul./dez. 2003. Disponível em:<http://revistas.univerciencia.org/index.php/revistaemquestao/ article/viewArticle/3638>. Acesso em: 28 nov. 2014.

JOAQUIM, Juliana Teixeira; MESQUITA, Cristiane. Rupturas do Vestir: articulações entre moda e feminismo. 2011. Revista DAPesquisa, n. 8, p. 643-659, Ago., 2010/ jul., 2011. Disponível em:<http://www.ceart.udesc. br/dapesquisa/files/05MODA_Juliana_Teixeira_Joaquim.pdf>. Acesso em 01 dez. 2014.

KOSSOY, Boris. Fotografia \& História. 5. ed. São Paulo: Ateliê Editorial, 2014.

MIRANDA, A. P. C. et al. Influenciadores e Hábitos de Mídia no Comportamento do Consumo de Moda. 1999. Disponível em:<http:// www2.anhembi.br/html/ead01/ contrucao_imagem_marca/pdf/ aula_02.pdf>. Acesso em: 27 nov. 2014.

MIRANDA, Ana Paula Celso de. Comportamento de Consumo em Vestuário de Moda Feminino: análise exploratória. 1998. Disponível em: <http://dspace.c3sl.ufpr.br:8080/ dspace/bitstream/ handle/1884/31884/R\%20-\%20D\%20-\%20ANA\%2OPAULA\%20 CELSO\%20DE\%20 MIRANDA.PDF? sequence=1\&isAllowed=y $>$. Acesso em: 5 maio 2015.

MIRANDA, Ana Paula Celso de. Consumo de moda: a relação pessoaobjeto. 2. ed. São Paulo: Estação das Letras e Cores, 2014.

REVISTA TPM. São Paulo: Editora Trip, n. 149, dez/jan. 2015.

REVISTA TPM. São Paulo: Editora Trip, n. 150, fev. 2015.

REVISTA TPM. São Paulo: Editora Trip, n. 151, mar. 2015.

REVISTA TPM. São Paulo: Editora Trip, n. 152, abr. 2015.

SALTARELLI, Beatriz Viana Lopes. A desconstrução do feminino no Manifesto TPM. Belo Horizonte. 2012. Disponível em: <https:// 
biasaltarellisa.files.wordpress.com/2012/08/a-desconstruc3a7c3a3odo-feminino-no-manifesto-tpm-_-beatriz-saltarelli.pdf $>$. Acesso em: 27 maio 2015.

SCHMITZ, Daniela Maria. Mulher na moda: recepção e identidade feminina nos editoriais de moda da revista Elle. São Leopoldo, 2007. Disponível em: <http://www.livrosgratis.com.br/arquivos_livros/ cp048213.pdf>. Acesso em: 1 dez. 2014. 